\title{
Multicriteria Reconfiguration of Distribution Network with Distributed Generation
}

\author{
N. I. Voropai ${ }^{1}$ and B. Bat-Undraal ${ }^{2}$ \\ ${ }^{1}$ Electric Power Systems Department, Energy Systems Institute, Russian Academy of Sciences, Siberian Branch, 130 Lermontov Street, \\ Irkutsk 664033, Russia \\ ${ }^{2}$ Power Engineering School, Mongolian University of Science and Technology, Baga Toiruu, VIII khoroo, Sukhbaatar, \\ Ulaanbaatar 210646, Mongolia
}

Correspondence should be addressed to N. I. Voropai, voropai@isem.sei.irk.ru

Received 2 August 2011; Revised 3 November 2011; Accepted 7 November 2011

Academic Editor: Edgar Carreno

Copyright (C) 2012 N. I. Voropai and B. Bat-Undraal. This is an open access article distributed under the Creative Commons Attribution License, which permits unrestricted use, distribution, and reproduction in any medium, provided the original work is properly cited.

\begin{abstract}
The paper addresses the problem of multicriteria reconfiguration of distribution network with distributed generation according to the criterion of minimum power loss under normal conditions and the criterion of power supply reliability under postemergency conditions. Efficient heuristic and multicriteria methods are used to solve the problem including advanced ant colony algorithm for minimum loss reconfiguration of distribution network, the sorting-out algorithm of cell formation for island performing in postemergency network, and the successive concessions method for multicriteria decision making. Demonstration studies have been carried out for the Central Power System of Mongolia.
\end{abstract}

\section{Introduction}

Distribution networks are normally operated according to radial schemes. The problem of distribution network reconfiguration aimed at determining the most rational reconfiguration is as a rule solved by the criteria of minimum active power losses in the network, minimum undersupplied power, and minimum time for power supply restoration [1]. A review of reconfiguration methods that include classical methods of mathematical programming and modern heuristic methods based on artificial intelligence (genetic algorithms, simulated annealing, tabu search, ant colony methods, etc.) is given in [2]. In many cases the problem is considered as a multicriteria one with reliability criterion formulated through damages to consumers $[3,4]$ and so forth.

In the last decade much attention has been paid to disatributed generation connected to distribution network $[5,6]$ and so forth. The main factors stimulating the development of distributed generation are as follows:

(i) adaptation of consumers to market uncertainty in electricity industry development and electricity prices which fosters a decrease in risks of power shortage and increase of energy security;

(ii) enhancement of adaptability of electric power systems to the uncertainty of market conditions and, hence, decrease of investment risks;

(iii) emergence of new highly efficient energy technologies (gas turbines and combined-cycle units);

(iv) a growing share of gas in the fuel mix of power plants;

(v) tightening the environmental requirements to encourage the use of renewable energy sources (hydro, wind, biomass, etc.) with government support.

Distributed generation offers the possibility of maintaining voltage levels at nodes of distribution network, decreasing active and reactive power losses in the network, providing higher level of power supply reliability by maintaining power supply from distributed generation to some consumers in the case of emergency disconnection of the main supply point in the power supply system (islanding) $[5,7,8]$.

Thus the coordination problem arises in controlling normal conditions of distribution network with distributed 
generation through the network reconfiguration, to provide minimum power losses and to meet the required voltage and current limits, as well as in controlling postemergency conditions through islanding, to provide minimum power shortage due to the loss of supply substation of main power grid (main supply point). Such multicriteria problems cannot always be reduced to a one-criterion statement by introducing weighted coefficients for individual criteria. In this paper this problem is solved by the method of successive concessions [9]. The method of ant colony is used for distribution network reconfiguration. Islanding is performed by forming cells [10] and load flow is calculated by the backward/forward sweep algorithm [7].

\section{Technology of Study}

2.1. General Approach. A general approach to control coordination of normal and postemergency conditions of distribution network including distributed generation is as follows.

Under normal conditions the control aims to reconfigure the distribution network by opening loops. The minimum of active power losses in the network is given by the following criterion:

$$
\sum_{l \in L} R_{l k} I_{l k}^{2} \longrightarrow \min , \quad k \in K
$$

where $K$ is a set of considered normal conditions according to the load curves of consumers and loading of distributed generation plants; $L$ is the number of branches in the network; $R_{l k}$ and $I_{l k}$ are active resistance and current in branch $l$ for operation conditions $k$.

Under postemergency conditions, if the main supply point is lost, the problem of islanding arises with the islands including distributed generation plants that operate for a balanced load. The criterion of islanding is the minimum power shortage in the postemergency conditions:

$$
\left(\sum_{n \in N} P_{n k}-\sum_{n^{*} \in N^{*}} P_{n^{*} j}\right) \longrightarrow \min , \quad k \in K, j \in J,
$$

where $J$ is a set of considered postemergency conditions with the main supply point lost; $P_{n k}$ is the load at node $n$ in the network under normal condition $k ; P_{n^{*} j}$ is the load at node $n^{*}$ in the postemergency condition $j$ of the network part including $N^{*}$ nodes, that belong to all islands; $N$ is the number of network nodes.

In control coordination of normal and postemergency conditions of distribution network, an important problem is to check whether the constraints on voltage levels at nodes and currents in network branches are met under both normal and postemergency conditions:

$$
\begin{gathered}
V_{n k \min } \leq V_{n k} \leq V_{n k \max }, \\
V_{n j \min } \leq V_{n j} \leq V_{n j \max }, \\
I_{l k} \leq I_{l k \max }, \\
I_{l j} \leq I_{l j \max } .
\end{gathered}
$$

Instead of (5) and (6), the values of power transmitted by the network branches can be controlled using similar inequalities.

Constraints (3)-(6) in the optimization of criteria (1) and (2) are checked on the basis of radial network power flow calculations. The calculations employ backward/forward sweep algorithm with respect to distributed generation plants connected to the distribution network [7]. In order to minimize the number of such calculations, the interval implementation of backward/forward sweep algorithm [11] is applied which allows the ranges of voltage and current values to be obtained for groups of conditions.

There are two specific features of the problem related to islanding and determining postemergency conditions. The first one concerns the presence of constraints (4) and (6), which means different requirements for voltage levels at nodes and maximum load of network branches in the postemergency conditions as compared to the normal conditions. The second one related to islanding is implementation of the principle of maintaining power supply, first of all, to the most important consumers at the distribution network nodes.

One of the important control coordination problems of normal and postemergency conditions of distribution networks is minimization of switchings while passing from normal to postemergency conditions. This is important in terms of minimizing the number of switching devices, their possible failures, and personnel's errors. Therefore, the optimization problem (1)-(6) is a complex two-criterion problem. Let us consider an expedient approach to its solution.

A widely used approach is the consideration for power supply reliability through the damages due to power undersupply which allows the multicriteria problem to be reduced to a one-criterion one $[3,4]$ and so forth. To this end it is necessary to have reliable estimates of specific damages due to power supply interruption for different consumers. In reality these estimates cannot be obtained for all types of consumers; particularly it concerns the consumers with production processes where power supply interruptions may pose a threat to the life of people or to the environment. Therefore in a general case criteria (1) and (2) should be considered as independent and irreducible to one complex criterion. In the paper the method of successive concessions is used as a method for solving the two-criterion problem (1)-(6). The minimization by criterion (1) with regard to constraints (3) and (5) is carried out by the ant colony method, islanding (subproblems (2), (4), and (6)) by the combinatorial algorithm through formation of cells.

2.2. Minimum Loss Reconfiguration. Ant colony algorithm is a multiagent system in which the behavior of each single agent, called artificial ant, is inspired by the behavior of real ants [12]. Ant colony algorithm is one of the most successful examples of swarm intelligent systems and has been applied to many combinatorial optimization problems. Ant colony algorithm has been used lately to solve minimum loss reconfiguration problem [13-17]. 


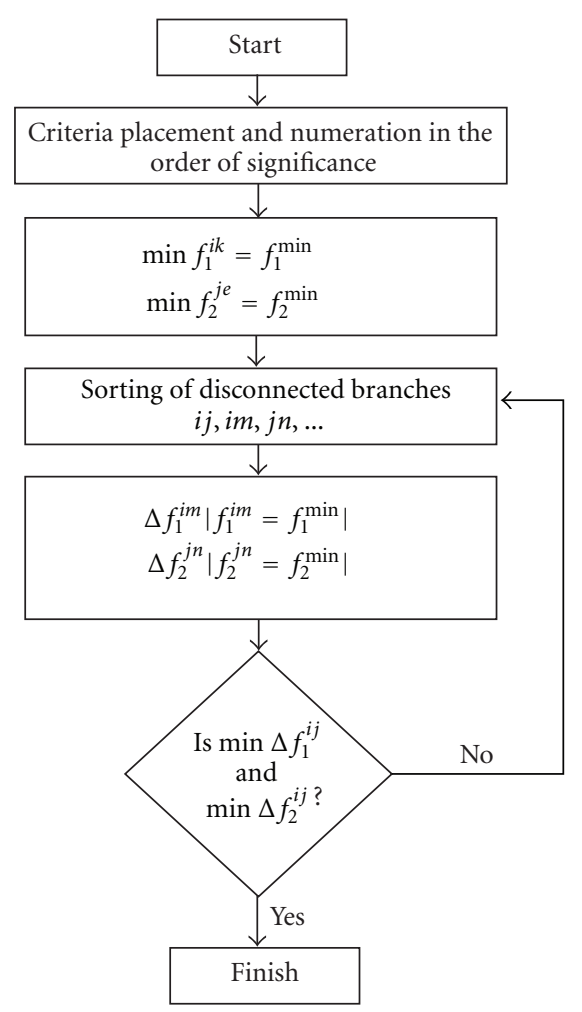

FIGURE 1: Flowchart of modified method of successive concessions.

The idea of the ant colony algorithm is rather thoroughly presented in [12] and given in [13-17]; therefore we will not describe it here.

The type of the ant colony algorithm implementation is determined by what is understood by the track passed by ants. In $[13,14]$ active power losses in the entire network are taken as a track length. In $[15,17]$ the track length is determined by the resistance of one branch and the algorithm consequently goes along the network graph starting from the main supply point of the power supply system.

In the first case the point of network disconnection is chosen by the roulette rule, with the disconnection point probability determined by [13]

$$
P_{m(t)}= \begin{cases}\frac{\eta(t)^{\beta} / \tau(t)}{\sum_{s \in I_{m}(l)}\left(\eta(s)^{\beta} / \tau(s)\right)}, & \text { if } s \in J_{m}(l), \\ 0, & \text { otherwise, }\end{cases}
$$

where $t(s)$ is a pheromone level; $h(s)$ is the so-called visibility, a value inverse to the length of track passed by ants; $m$ is the number of ants; $J_{m}(l)$ is the list of branches in loop $l ; \beta$ is a parameter determining relative priority of pheromone; $t$ determines a currently considered branch or a current iteration of the algorithm.

In [14], another, more complex, algorithm is used. It is related to the hypercube ant colony optimization framework.

In the second case (in [15-17]), the roulette rule is used to choose the next branch in the network graph to be considered. There are different forms of realization of roulette rule.
This paper employs the approach suggested in [13], but unlike [13] here load flow is calculated in each iteration of the ant colony algorithm by the backward/forward sweep method, and constraints (3) and (5) are checked. In the event that the constraints are not met, the branch considered as a candidate for disconnection is excluded from consideration.

2.3. Islanding. In the problem of distributed generation islanding for an equivalent load in the event that power supply from supply substation of the main network is lost, it is necessary to take into account a number of requirements.

(1) The distributed generation and load should be balanced in order to fully use and not to overload distributed generation. The condition of power balance in the island is found by the sorting-out algorithm through formation of cells [10]. For each cell meeting the condition

$$
\sum P_{S n}-\sum P_{L n} \geq 0
$$

is checked, where $S$ and $L$ are the indices of sources and loads at cell, and $n$ is a cell index.

(2) Cells are formed by connecting, first of all, the nearest loads, and the remoteness of load nodes is estimated by the total resistance of branches connecting source to consumer.

(3) While forming the cells first of all power is supplied to the most important consumers. 


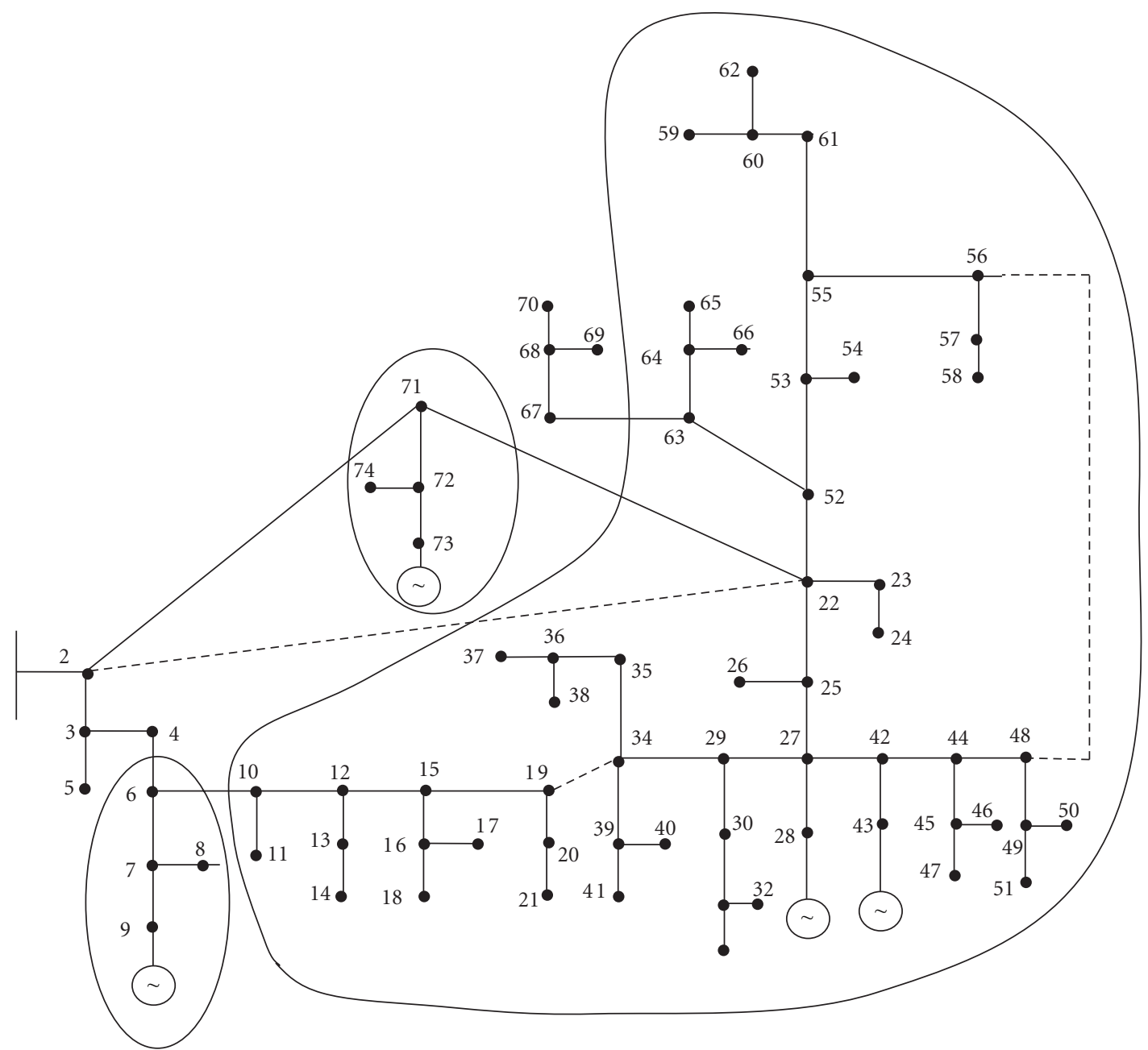

Figure 2: Points of electric network tripping in normal conditions (dashed lines) and composition of islands in the postemergency conditions (encircled).

(4) At each step of the sorting-out algorithm, the load flow in the island is calculated and constraints (4) and (6) are met. In the event that these constraints are not met, formation of an island is stopped at the previous step.

In order to eliminate the inconsistency between the second and third requirements, the third requirement is considered a priority one.

2.4. Method of Successive Concessions. The general procedure of solving a multicriteria problem by the method of successive concessions is as follows [9].

(i) All partial criteria are placed and numbered in the order of their relative significance.

(ii) The first most important criterion is optimized.

(iii) The value of the admissible deviation from the optimum of the first criterion (concession) is set.

(iv) The second important partial criterion is optimized provided that the value of the first criterion should not differ from the optimal value by more than a value of the concession set. (v) Similarly the value of concession for the second criterion is set and the third important criterion is optimized and so on.

In a general case the presented procedure can include, when necessary, several iterations converging to a satisfactory trade-off solution.

In the paper the general method of successive concessions was modified by taking into account the specificity of the studied problem. The modified procedure includes the following four steps.

(1) All partial criteria are placed and numbered in the order of their relative significance. On our case the order of criteria is as follows:

$$
f_{1}=\sum_{l \in L} R_{l k} I_{l k}^{2} \longrightarrow \min , \quad k \in K
$$

$$
f_{2}=\left(\sum_{n \in N} P_{n k}-\sum_{n^{*} \in N^{*}} P_{n^{*} j}\right) \longrightarrow \min , \quad k \in K, j \in J .
$$


TABLE 1

\begin{tabular}{|c|c|c|c|c|c|}
\hline Nodes & $U, \mathrm{kV}$ & $P_{L}, \mathrm{MW}$ & $Q_{L}$, MVA & $P_{g}, \mathrm{MW}$ & $P_{g}$, MVA \\
\hline 1 & 242 & - & - & - & - \\
\hline 2 & 220 & - & - & - & - \\
\hline 3 & 110 & - & - & - & - \\
\hline 4 & 110 & 16.8 & 7.5 & - & - \\
\hline 5 & 35 & - & & - & - \\
\hline 6 & 110 & 24.8 & 8.8 & - & - \\
\hline 7 & 35 & - & - & - & - \\
\hline 8 & 110 & 1.3 & 2.4 & - & - \\
\hline 9 & 6 & 6.0 & 7.3 & 33.6 & 11.1 \\
\hline 10 & 6 & - & - & - & - \\
\hline 11 & 6 & 2.1 & 0.8 & - & - \\
\hline 12 & 6 & - & - & - & - \\
\hline 13 & 6 & - & - & - & - \\
\hline 14 & 6 & 2.9 & 1.1 & - & - \\
\hline 15 & 6 & - & - & - & - \\
\hline 16 & 6 & - & - & - & - \\
\hline 17 & 110 & 0.6 & 0.1 & - & - \\
\hline 18 & 6 & 2.9 & 1.1 & - & - \\
\hline 19 & 6 & - & - & - & - \\
\hline 20 & 6 & - & - & - & - \\
\hline 21 & 6 & 0.2 & 0.1 & - & - \\
\hline 22 & 10 & - & - & - & - \\
\hline 23 & 10 & - & - & - & - \\
\hline 24 & 10 & - & - & - & - \\
\hline 25 & 10 & - & - & - & - \\
\hline 26 & 35 & - & - & - & - \\
\hline 27 & 110 & 95.7 & 50.8 & & - \\
\hline 28 & 10 & - & - & 47.9 & 18.2 \\
\hline 29 & 10 & - & - & 79.7 & 89.1 \\
\hline 30 & 10 & - & - & - & - \\
\hline 31 & 10 & - & - & - & - \\
\hline 32 & 35 & 0.7 & 0.3 & - & - \\
\hline 33 & 10 & 2.2 & 1.2 & - & - \\
\hline 34 & 10 & - & - & - & - \\
\hline 35 & 10 & - & - & - & - \\
\hline 36 & 10 & - & - & - & - \\
\hline 37 & 10 & 0.1 & 0.1 & & - \\
\hline 38 & 110 & 6.2 & 3.0 & - & - \\
\hline 39 & 6 & - & - & - & - \\
\hline 40 & 110 & 0.2 & 0.1 & - & - \\
\hline 41 & 6 & 0.1 & 0.1 & - & - \\
\hline 42 & 6 & - & - & 73.9 & 29.0 \\
\hline 43 & 6 & - & - & - & - \\
\hline 44 & 6 & - & - & - & - \\
\hline 45 & 6 & - & - & - & - \\
\hline 46 & 6 & 1.6 & 0.7 & - & - \\
\hline 47 & 10 & 5.9 & 2.4 & - & - \\
\hline 48 & 10 & - & - & - & - \\
\hline 49 & 10 & - & - & - & - \\
\hline 50 & 35 & 21.1 & 8.5 & - & - \\
\hline 51 & 10 & 7.9 & 2.7 & - & - \\
\hline 52 & 10 & - & - & - & - \\
\hline
\end{tabular}

TABle 1: Continued.

\begin{tabular}{lccccc}
\hline Nodes & $U, \mathrm{kV}$ & $P_{L}, \mathrm{MW}$ & $Q_{L}, \mathrm{MVA}$ & $P_{g}, \mathrm{MW}$ & $P_{g}, \mathrm{MVA}$ \\
\hline 54 & 10 & - & - & - & - \\
55 & 10 & - & - & - & - \\
56 & 10 & - & - & - & - \\
57 & 10 & - & - & - & - \\
58 & 10 & 4.9 & 2.3 & - & - \\
59 & 10 & - & - & - & - \\
60 & 6 & - & - & - & - \\
61 & 6 & - & - & - & - \\
62 & 35 & - & - & - & - \\
63 & 10 & - & - & - & - \\
64 & 10 & - & - & - & - \\
65 & 110 & 16.9 & 7.5 & - & - \\
66 & 35 & - & - & - & - \\
67 & 10 & - & - & - & - \\
68 & 10 & - & - & - & - \\
69 & 110 & - & - & - & - \\
70 & 35 & - & - & - & - \\
71 & 10 & - & - & - & - \\
72 & 10 & - & - & - & - \\
73 & 35 & 26.8 & 8.8 & - & - \\
74 & 110 & 108.4 & 58.6 & - & - \\
\hline
\end{tabular}

(2) The first most important criterion $f_{1}$ is minimized by the ant colony algorithm as it is described in Section 2.2. The disconnected branches are determined as a result of minimization of criterion $f_{1}$.

(3) The second criterion $f_{2}$ is minimized by the algorithm through formation of cells as it is described in Section 2.3. The other disconnected branches are determined which differ from the disconnected branches determined by minimization of criterion $f_{1}$.

(4) The combinatorial sorting algorithm is used to search for the disconnected branches which are acceptable from the point of view of both criteria $f_{1}$ and $f_{2}$ with the minimal concessions of both criteria.

The flowchart of modified method of successive concessions is shown in Figure 1.

\section{Case Study}

The studied network is a simplified network of the Central Power System of Mongolia (Figure 2). The data of network are presented in Tables 1 and 2. The Gusinoozyersk thermal power plant (TPP) (node 1) that is included in the Unified Power System of Russia and supplies electricity to the Central Power System of Mongolia transmission line (branch 1-2) is conditionally taken as the main supply point. In the Central Power System of Mongolia there are 4 small operating thermal power plants of similar capacity which are really distributed generation units.

Network reconfiguration by using the criterion of minimum active power losses (1) on the basis of constraints (3) 
TABLE 2

\begin{tabular}{|c|c|c|c|}
\hline \multicolumn{2}{|c|}{ Branches } & \multirow{2}{*}{$R, \mathrm{Om}$} & \multirow{2}{*}{$X, \mathrm{Om}$} \\
\hline$i$ & $j$ & & \\
\hline 1 & 2 & 27.0 & 107.0 \\
\hline 2 & 3 & 1.4 & 100.0 \\
\hline 2 & 22 & 29.1 & 115.3 \\
\hline 2 & 71 & 16.1 & 63.6 \\
\hline 3 & 4 & 1.4 & 0 \\
\hline 3 & 5 & 2.9 & 193.0 \\
\hline 4 & 6 & 1.1 & 3.2 \\
\hline 6 & 7 & 0.7 & 27.0 \\
\hline 6 & 10 & 12.1 & 19.0 \\
\hline 7 & 8 & 0.7 & 0 \\
\hline 7 & 9 & 0.7 & 16.5 \\
\hline 10 & 11 & 7.9 & 138.9 \\
\hline 10 & 12 & 11.4 & 17.9 \\
\hline 12 & 13 & 1.1 & 1.65 \\
\hline 13 & 14 & 42.6 & 508.2 \\
\hline 12 & 15 & 6.9 & 10.9 \\
\hline 15 & 16 & 10.0 & 225.0 \\
\hline 15 & 19 & 5.5 & 8.7 \\
\hline 16 & 17 & 10.0 & 0 \\
\hline 16 & 18 & 10.0 & 131.0 \\
\hline 19 & 20 & 1.8 & 2.9 \\
\hline 19 & 34 & 9.3 & 14.6 \\
\hline 20 & 21 & 42.6 & 508.2 \\
\hline 22 & 23 & 0.7 & $2 / 1$ \\
\hline 22 & 25 & 0.5 & 48.6 \\
\hline 22 & 52 & 1.5 & 6.1 \\
\hline 23 & 24 & 5.7 & 12.9 \\
\hline 25 & 26 & 1.0 & 82.5 \\
\hline 25 & 27 & 0.5 & 0 \\
\hline 27 & 28 & 0.4 & 12.3 \\
\hline 27 & 29 & 17.2 & 27.0 \\
\hline 27 & 42 & 0.3 & 0.8 \\
\hline 29 & 30 & 1.5 & 2.4 \\
\hline 29 & 34 & 8.1 & 12.7 \\
\hline 30 & 31 & 5.3 & 142.0 \\
\hline 31 & 32 & 5.3 & 0 \\
\hline 31 & 33 & 5.3 & 82.0 \\
\hline 34 & 35 & 8.9 & 13.9 \\
\hline 34 & 39 & 5.3 & 142.0 \\
\hline 35 & 36 & 5.3 & 142.0 \\
\hline 36 & 37 & 5.3 & 82.0 \\
\hline 36 & 38 & 5.3 & 0 \\
\hline 39 & 40 & 5.3 & 82 \\
\hline 39 & 41 & 5.3 & 82.0 \\
\hline 42 & 43 & 1.4 & 34.7 \\
\hline 42 & 44 & 0.3 & 0.9 \\
\hline 44 & 45 & 1.5 & 54.0 \\
\hline 44 & 48 & 0.4 & 1.1 \\
\hline
\end{tabular}

TABle 2: Continued.

\begin{tabular}{|c|c|c|c|}
\hline \multicolumn{2}{|c|}{ Branches } & \multirow{2}{*}{$R, \mathrm{Om}$} & \multirow{2}{*}{$X, \mathrm{On}$} \\
\hline$i$ & $j$ & & \\
\hline 45 & 46 & 1.5 & 0 \\
\hline 45 & 47 & 1.5 & 33.0 \\
\hline 48 & 49 & 0.7 & 27.0 \\
\hline 48 & 56 & 0.3 & 0.8 \\
\hline 52 & 53 & 0.2 & 24.3 \\
\hline 52 & 63 & 11.3 & 44.9 \\
\hline 53 & 54 & 1.0 & 82.5 \\
\hline 53 & 55 & 0.5 & 0 \\
\hline 55 & 56 & 0.1 & 0.1 \\
\hline 55 & 61 & 3.3 & 5.1 \\
\hline 56 & 57 & 0.5 & 0.7 \\
\hline 57 & 58 & 7.9 & 138.9 \\
\hline 59 & 60 & 0.7 & 16.5 \\
\hline 60 & 62 & 0.7 & 0 \\
\hline 63 & 64 & 1.4 & 100.0 \\
\hline 63 & 67 & 24.1 & 78.6 \\
\hline 64 & 65 & 1.4 & 0 \\
\hline 67 & 68 & 0.7 & 50.0 \\
\hline 68 & 69 & 0.7 & 0 \\
\hline 68 & 70 & 1.4 & 96.5 \\
\hline 71 & 72 & 0.2 & 24.3 \\
\hline 72 & 73 & 0.5 & 41.2 \\
\hline 72 & 74 & 0.2 & 0 \\
\hline
\end{tabular}

and (5) allows the points of network loop disconnection to be revealed. These are branches 2-22, 19-34, and 48-56 shown in Figure 2 by dashed lines.

Then the postemergency conditions in the Central Power System of Mongolia are studied for the case of power supply loss from the Gusinoozyersk TPP. Here the generators of the Central Power System of Mongolia cover part of the load and as a result three independent islands are formed by criterion (2) (see Figure 2). For all the islands constraints (4) and (6) are met.

Comparison of the disconnection points in the normal and postemergency conditions shows that the disconnection of branch 2-22 coincides in both cases. The disconnection of branch $48-56$ is of no concern for the postemergency conditions, since it does not influence on island formation.

Consider branch 19-34. In normal conditions this branch has to be tripped from the standpoint of minimum active power losses. Their value in this case is $14.34 \mathrm{MW}$. In the postemergency conditions the other branch $6-10$ is tripped. When the loop is open on this branch, in the normal conditions the power losses are $11 \%$ higher than the optimal ones. Such an increase in losses is not allowed.

Find an acceptable concession from the criterion of minimum active power losses (1) in the normal conditions by the island adjustment. Consider the variant of disconnection of branch 15-19 with the corresponding reduction of the island by excluding nodes $10,11,12,13,14,16,17$, and 18 from it. The disconnection of branch $15-19$ causes an 


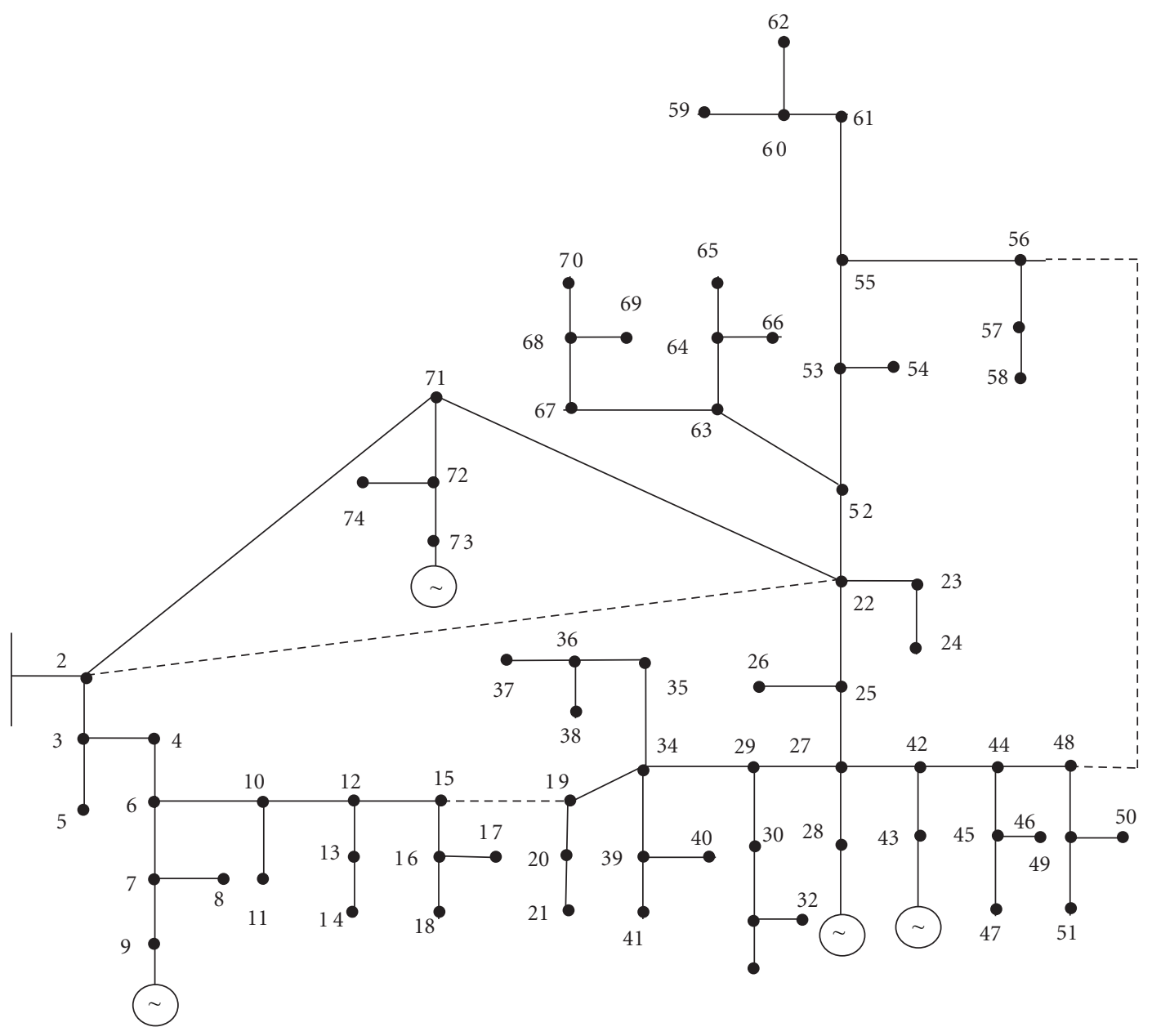

FIgURE 3: Optimal points of electric network tripping in the context of requirements of the normal and postemergency conditions.

increase in losses in the normal conditions by somewhat less than $5 \%$ in comparison with the optimal value that is acceptable.

We try to expand the island by an additional concession on the basis of criterion (1). To do this, we open branch 1215 instead of branch 15-19. In this case in the normal conditions the losses rise by the value above $7 \%$ as compared to the optimal value, but such an increase is unacceptable.

Thus, in accordance with criteria (1) and (2) the opening of branches 2-22, 48-56, and 15-19 (Figure 3) is a trade-off solution and here the concession value by criterion (1) is acceptable.

\section{Conclusion}

In electricity supply systems with distributed generation that is connected to the distribution electric network, a complex problem arises which provide efficient operation of electricity supply systems in the normal conditions and reliable power supply to consumers in the postemergency conditions at a loss of the main supply point. This multicriteria problem is solved in the paper by applying the modified method of successive concessions. The efficiency of power system operation is studied based on the criterion of minimum active power losses by network reconfiguration that is performed by the developed ant colony method. In the postemergency conditions the islanding problem is solved by using the cell formation method. The studies carried out for the Central Power System of Mongolia have shown the efficiency of the approach described in the paper.

A general technology to control coordination of normal and postemergency conditions of distribution network with distributed generation takes into account a set of considered normal conditions according to the load curves of consumers and loading of distributed generation plants and a set of considered postemergency conditions with the main supply point lost. One of the important control coordination problems considering the above mentioned two sets of conditions is minimization of switchings while passing from normal to postemergency conditions. Proposed technology and algorithms dive the possibility of solving this problem.

Possible future work could be dealt with more detailed consideration of customer load uncertainty, variety of power output from distributed generation units based on wind or/and solar energy, minimization of both active power losses 
and fuel usage at thermal distributed power plants, and other related problems. The authors hope for the success in these areas of research.

\section{Acknowledgments}

This paper was supported by the Grants of Leading Scientific School of RF no.1857.2008.8 and Russian Foundation for Basic Researches no.90-08-91330.

\section{References}

[1] A. Cárcamo-Gallardo, L. García-Santander, and J. E. Pezoa, "Greedy reconfiguration algorithms for medium-voltage distribution networks," IEEE Transactions on Power Delivery, vol. 24, no. 1, pp. 328-337, 2009.

[2] M. A. Tavakoli, M. R. Hanhifam, H. Lesani, S. Sanakhan, and E. Javan, "Review on reconfiguration methods of electric distribution networks," in Proceeding of the Technical and Physical Problems in Power Engineering Conference, Ankara, Turkey, May 2006.

[3] Y. T. Hsiao, "Multiobjective evolution programming method for feeder reconfiguration," IEEE Transactions on Power Systems, vol. 19, no. 1, pp. 594-599, 2004.

[4] Y. Y. Hong and S. Y. Ho, "Determination of network configuration considering multiobjective in distribution systems using genetic algorithms," IEEE Transactions on Power Systems, vol. 20, no. 2, pp. 1062-1069, 2005.

[5] N. Jenkins, R. Allan, P. Crossley, D. Kirschen, and G. Strbac, Embedded Generation, IEE Press, London, UK, 2000.

[6] T. Ackermann, G. Andersson, and L. Söder, "Distributed generation: a definition," Electric Power Systems Research, vol. 57, no. 3, pp. 195-204, 2001.

[7] M. Eremia, Electric Power Systems, vol. 1, Editura Academiei Romane, Bucuresti, Romania, 2006.

[8] T. Funabashi, K. Koyanagi, and R. Yokoyama, "A review of islanding detection methods for distributed resources," in Proceeding of IEEE Bologna Power Tech Conference, p. 6, Bologna, Italy, June 2003.

[9] C.-L. Hwang and A. S. Masud, Multiple Objective Decision Making. Methods and Applications-State of the Art Survey, Springer, Berlin, Germany, 1979.

[10] Y. Lu, X. Yi, J. Wu, and X. Lin, "An intelligent islanding technique considering load balance for distribution system with DGs," in IEEE Power Engineering Society General Meeting (PES '06), June 2006.

[11] N. I. Voropai and B. Bat-Undral, "Load flow calculation in a radial electrical network using the interval method," Electrichestvo, pp. 64-66, 2008 (Russian).

[12] M. Dorigo, V. Maniezzo, and A. Colorni, "Ant system: optimization by a colony of cooperating agents," IEEE Transactions on Systems, Man, and Cybernetics B, vol. 26, no. 1, pp. 29-41, 1996.

[13] Y.-J. Jeon, J.-Ch. Kim, and S.-Y. Lee, "Application of ant colony algorithm for network reconfiguration in distribution systems," in Proceedings of IFAC Symposium on Power Plants and Power Systems Control, Seoul, South Korea, September 2003.

[14] E. Carpaneto and G. Chicco, "Distribution system minimum loss reconfiguration on the hyper-cube ant colony optimization framework," in Proceedings of the World Energy System Conference, pp. 167-174, Torino, Italy, July 2006.
[15] J. Olamaei, T. Niknam, G. Gharehpetian, and E. Jamshidpour, "An approach based on ant colony optimization for distribution feeder reconfiguration considering distributed generation," in Proceedings of the International Conference on Electricity Distribution (CIRED '07), Vienna, Austria, May 2007.

[16] X. Yiqin and T. Jia, "A new search approach in ant colony system algorithm for network reconfiguration of distribution systems," in Proceedings of the International Conference on Deregulation, Restructuring, and Power Technologies (DRPT '2008), Nanjing, China, April 2008.

[17] C. F. Chang, "Reconfiguration and capacitor placement for loss reduction of distribution systems by ant colony search algorithm," IEEE Transactions on Power Systems, vol. 23, no. 4, pp. 1747-1755, 2008. 

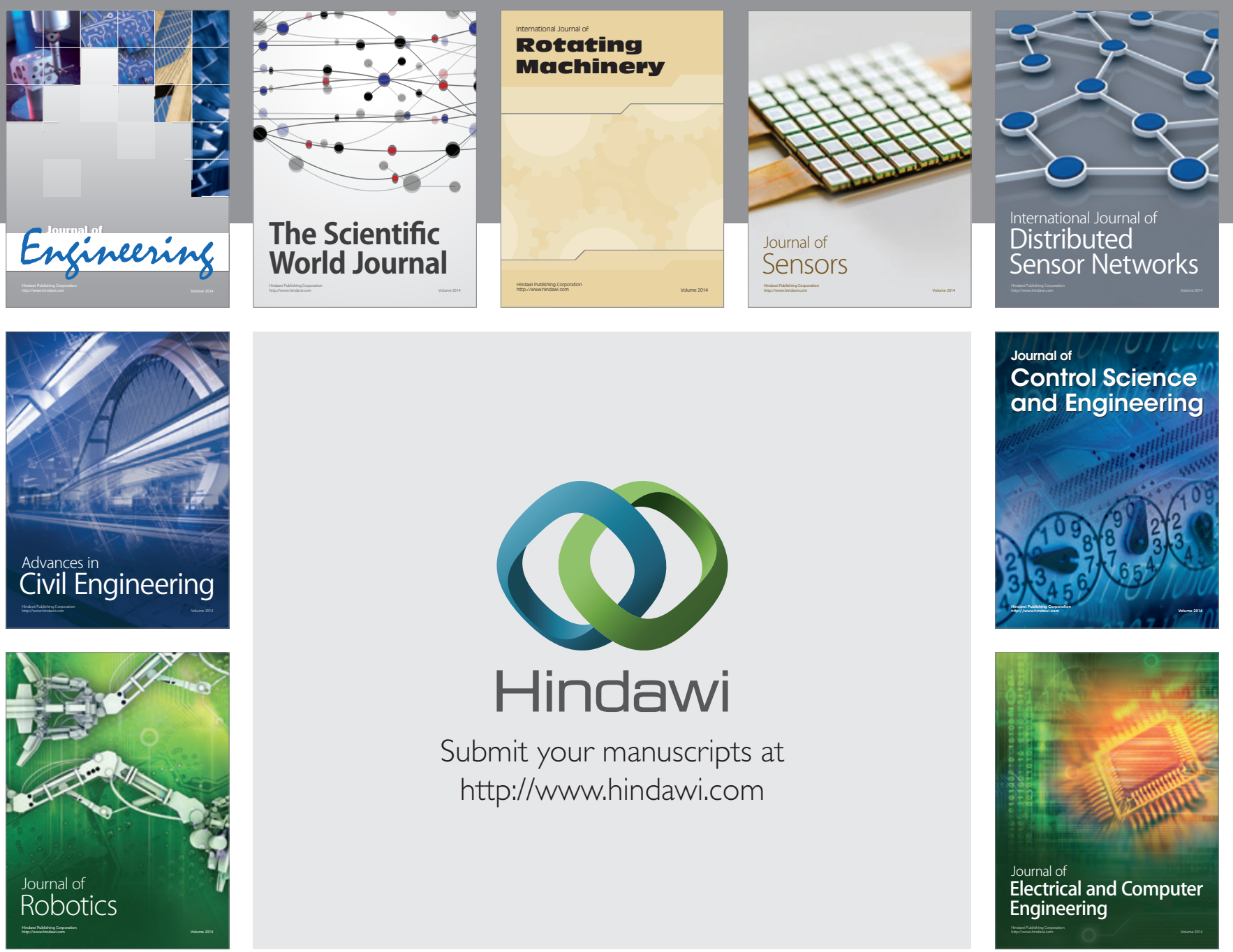

Submit your manuscripts at

http://www.hindawi.com
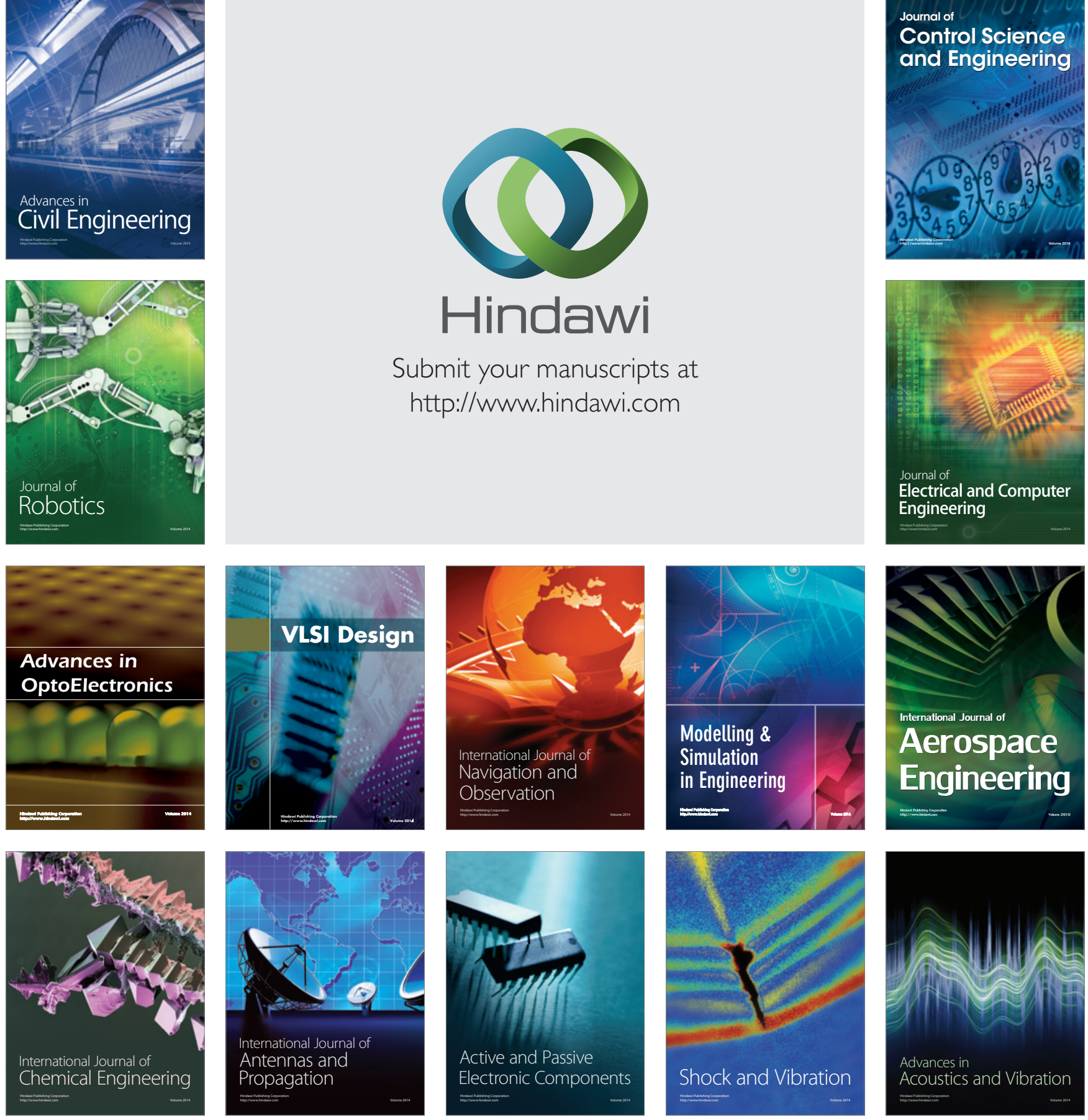